\title{
Actividad publicitaria en la revista La Esfera (1914-1931). Un estudio por sectores
}

\author{
Raquel VALBUENA ÁlVAREZ \\ Ministerio de Educación, Cultura y Deporte \\ raquel.valbuena@mecd.es \\ Antonia SALVAdor Benítez \\ Facultad de Ciencias de la Documentación. \\ Universidad Complutense de Madrid \\ asalvador@ccinf.ucm.es
}

Recibido: 06/04/2014

Aceptado: 20/05/2014

\section{RESUMEN}

Se presenta una introducción sobre la publicidad ilustrada en la prensa de finales del siglo XIX y los resultados de un estudio cuantitativo del volumen publicitario por sectores en la revista ilustrada $L a$ Esfera a lo largo de sus diecisiete años de trayectoria (1914-1931). El estudio se llevó a cabo mediante el vaciado y el análisis de todos anuncios publicados en dicha revista. Entre los resultados obtenidos destaca que los sectores con mayor presencia publicitaria son el editorial, el farmacéutico y la perfumería.

Palabras clave: Análisis publicitario, Anuncios ilustrados, La Esfera, Prensa ilustrada, Publicidad, 1914-1931

\section{Advertising activity at La Esfera Magazine (1914-1931). A study section}

\begin{abstract}
This article offers an introduction about illustrated advertising which was published in the last half of the $19^{\text {th }}$ century in the Spanish press and the results of a quantitative study of advertising volume by sectors in the illustrated magazine La Esfera throughout their seventeen years career (1914-1931). The study was carried out through the analysis of all advertisements which were published in the magazine. Among the results obtained it's worth to highlight that the greatest number of advertisements are of the publishing, the pharmaceutical and perfumery sectors.
\end{abstract}

Keywords: Advertising, Advertising analysis, Illustrated magazines, Illustrated advertisements, La Esfera, 1914-1931. 


\section{INTRODUCCIÓN}

El origen de la publicidad como actividad comercial tiene lugar en el siglo XIX, cuando el desarrollo industrial hace posible la producción en cadena, la reducción de los costes, y con ello, un considerable crecimiento del consumo, que se extendió más allá de los bienes de primera necesidad. Sin embargo, el progreso industrial no fue el único factor que propició el desarrollo del mercado publicitario. En este sentido Pérez Ruiz señala que "el segundo elemento positivo para el desarrollo de la publicidad fue la aparición de mensajes con marca en los periódicos"1. Y es que desde mediados del siglo XIX comienzan a incluirse en la prensa anuncios de los productos más notorios del momento, con un claro predominio de los remedios curativos y los productos de belleza. Estos primitivos reclamos publicitarios estaban constituidos básicamente por texto.

Pero será en las últimas décadas del siglo XIX cuando la prensa escrita experimente un importante auge protagonizado por la salida al mercado de nuevas publicaciones ilustradas como La Ilustración Española y Americana, Blanco y Negro, Nuevo Mundo y Mundo Gráfico, con un formato de presentación diferente y novedosos contenidos frente a la prensa diaria tradicional. A partir de este momento, la prensa -principal medio de comunicación de la época- comienza a incorporar la publicidad como fuente de financiación. Al mismo tiempo, la publicidad se va a servir de la prensa como medio de difusión para acercarse al público. Por tanto, se puede decir que entre la publicidad y la prensa ilustrada, comenzó a existir una relación de dependencia que hizo posible el desarrollo y el crecimiento de ambas industrias.

La ilustración aplicada a la publicidad empieza a adquirir una importante carga informativa y expresiva en las primeras décadas del siglo XX. A medida que se van perfeccionando las técnicas del fotograbado y la litografía, las ilustraciones comienzan a integrarse en los anuncios, que si bien, en un principio tenían una finalidad básicamente ornamental, irán ganando protagonismo frente al texto, que se irá reduciendo a breves enunciados a modo de eslogan.

Las ilustraciones, al igual que las fotografías o las imágenes en movimiento que se utilizan en la publicidad hoy en día, no sólo favorecen la comprensión del mensaje sino que también, constituyen un elemento de atracción que ayuda a transmitir al público una imagen de marca que conecte con sus valores. Tanto los personajes representados, como las acciones y situaciones en las que aparecen, revelan datos sobre el perfil del público consumidor de un determinado producto (sexo, edad, clase social, nivel de vida, profesiones, aficiones, preocupaciones, necesidades, valores...), los usos y aplicaciones de dichos productos, las ventajas que proporciona su consumo y qué características y valores interesa poner de

${ }^{1}$ PÉREZ RUIZ, M.A. La publicidad en España: anunciantes, agencias y medios (18501950). Madrid: Fragua, 2001. p. 19. 
relieve en cada época para lograr aumentar las ventas. Entre las primeras marcas iniciadoras de esta tendencia, destacaron las perfumerías Gal y Floralia, los automóviles Renault, la fábrica de relojes Carlos Coppel y el cinematógrafo Kok, entre otros.

En este trabajo se realiza un análisis de los anuncios publicados en la revista La Esfera en el periodo comprendido entre 1914-1931, con objeto de cuantificar el volumen publicitario por sectores. Asimismo se describen las características y elementos publicitarios de dichos anuncios y se proporciona una relación de las marcas y establecimientos que dentro de cada sector dedicaron mayores esfuerzos en la difusión de sus productos.

\section{METODOLOGÍA}

Para la recopilación y análisis de anuncios, se ha realizado un vaciado de la revista ilustrada La Esfera desde 1914 hasta 1931, fechas que comprenden la totalidad de números publicados. La selección de la revista La Esfera viene justificada en primer lugar, por tratarse de una de las revistas ilustradas más importantes de este periodo. En segundo lugar, por el papel destacado que jugó la publicidad en esta publicación, constituyendo el principal medio de financiación. Para comprobar si las características en la publicidad en La Esfera pueden aplicarse de forma genérica a la prensa ilustrada de la época se han revisado además sesenta ejemplares de las revistas ilustradas La Ilustración Española; Blanco y Negro; Mundo Gráfico y Nuevo Mundo, publicadas entre 1890 y 1930. Para ello se han valorado aspectos como el espacio y el lugar que ocupaban los anuncios en cada publicación, los sectores y productos con mayor carga publicitaria en cada revista, la tipología de los anuncios, los mensajes publicitarios utilizados y la presencia de ilustraciones.

Para la búsqueda y localización de ejemplares tanto de la revista La Esfera, como del resto de publicaciones consultadas, ha resultado fundamental el catálogo de la hemeroteca digital de la Biblioteca Nacional, que ha permitido la consulta de los números completos de cada publicación así como el análisis cuantitativo y cualitativo de los anuncios.

En relación al análisis de la publicidad en La Esfera se ha realizado un recuento del total de anuncios publicados en la revista en el periodo comprendido entre 1914-1931. Es necesario precisar que en este recuento no se han incluido los anuncios telegráficos ni la publicidad local de aparición ocasional, ya que no son el objeto de estudio de esta investigación ${ }^{2}$.

2 Con la expresión "publicidad local" nos referimos a aquellos anuncios que se incluyeron en secciones dedicadas a una provincia española en concreto y que se publicaron de forma puntual en La Esfera. 
A continuación se procede a la clasificación de los anuncios publicados por sectores productivos. Se han desestimado clasificaciones de uso actual en el ámbito publicitario como las de Infoadex por no estar adaptadas a los sectores de producción y comercialización del periodo de estudio. Se han tomado como referencia los trabajos de Pérez Ruiz (2001:100) que propone una clasificación basada en los nueve sectores con mayor inversión publicitaria en las primeras décadas del siglo $\mathrm{XX}^{3}$ y de Sánchez Vigil (2003:115) que ofrece una relación de las materias de los anuncios publicados en La Esfera ${ }^{4}$. El vaciado de la revista y el análisis de los anuncios publicados en ella permiten definir una serie de características de la publicidad en la prensa ilustrada de principios de siglo. Finalmente se proporciona una relación de las marcas y establecimientos de la época que dentro de cada sector hicieron uso de la publicidad en la prensa ilustrada para la promoción de sus productos.

\section{PRENSA ILUSTRADA Y PUBLICIDAD}

Las publicaciones periódicas comenzaron a buscar la rentabilidad económica y el modo de obtener ingresos no sólo con la venta de los ejemplares sino también con la inserción de publicidad entre sus páginas. Será el caso de periódicos surgidos a finales del siglo XIX y principios del siglo XX, como Las Provincias (Valencia, 1866), La Voz de Galicia (1872), La Vanguardia (1881), Heraldo de Madrid (1890), ABC (1905) y El Sol (1917).

El precio de las inserciones publicitarias dependía del número de palabras y de la sección en la que aparecían publicadas. Por citar un ejemplo, en 1917 en el diario $\mathrm{El} \mathrm{Sol}$ se cobraba una peseta por cada diez palabras y cinco céntimos más por cada palabra añadida y los anuncios situados en la sección general eran los más baratos $(0,30$ céntimos), mientras que un anuncio publicado en la sección de noticias costaba 2,50 pesetas. Esto pone de manifiesto la importancia otorgada ya en la época a la publicidad, así como a la elección de lugares estratégicos para la inserción de los anuncios dentro de las publicaciones.

${ }^{3}$ PÉREZ RUIZ, M.A. La publicidad en España: anunciantes, agencias y medios (18501950). Madrid: Fragua, 2001. Alimentación, Sector textil, Industria de la perfumería, Industria farmacéutica, Industria metalúrgica, Bebidas alcohólicas, Productos para el hogar, Grandes almacenes y Automóviles.

${ }^{4}$ SÁNCHEZ VIGIL, J.M. La Esfera: ilustración mundial (1915-1931). Madrid: Libris, 2003. La relación de materias por orden alfabético es la que sigue: Aguas y balnearios, Alimentación. Bebidas, Armería, Automóviles. Bicicletas, Bazar, Banca y seguros, Bodegas, Cine, Construcción, Curtidos, Deportes, Droguería, Ebanistería, Editorial, Electricidad, Enseñanza, Ferretería, Fontanería, Fotografía, Galería Arte, Hostelería, Hoteles, Hogar, Imprenta, Industria, Inmobiliaria, Joyería y relojería, Juguetes, Librería, Maquinaría, Medicina, Mobiliario, Música, Óptica, Papelería, Perfumería, Profesionales, Prensa, Publicidad, Repostería, Tabacos, Transporte, Turismo, Varios, Vestuario, Viajes. 
Según Pérez Ruiz (2001:145) la publicidad en prensa en las tres primeras décadas del siglo XX admitía hasta seis tipos distintos de localización: el anuncio preferente, insertado en cualquier página de la publicación pero con la peculiaridad de incluirse entre el texto, aislados del resto de los anuncios; los reclamos, que se localizaban en las primeras páginas; las gacetillas eran los anuncios publicados en la sección de información local; los anuncios generales, publicados casi siempre en las últimas páginas; los anuncios breves, como los actuales anuncios por palabras y el denominado anuncio disimulado, incluido entre la información simulando un artículo.

Si atendemos a esta clasificación, podemos afirmar que la mayor parte de los anuncios de las revistas ilustradas de esta época eran reclamos y anuncios generales, aunque en algunos números también se incluyeron gacetillas dedicadas a la publicidad local, generalmente Barcelona, Madrid, Santander y San Sebastián.

En La Ilustración Española y Americana los primeros anuncios se publican en el año 1873. La publicidad en esta revista aparece de forma irregular y solía situarse en la última página de la publicación, aunque también se han localizado algunos anuncios en la primera página y ocupando pequeños espacios de algunas secciones. El número de anuncios solía oscilar entre los veinte y los cuarenta en las tres últimas décadas del siglo XIX. Conforme avanza el siglo XX comienzan a normalizarse, tanto en tipología, como en espacio y extensión. Así, nos encontramos ya una sección propia para la publicidad, en las dos últimas páginas de cada número, con una media de entre diez y veinte anuncios por número. Algunas de las marcas con presencia habitual son el Agua Solares, el Agua Carabaña, los tés Horniman, el Coñac Caballero, la sidra El Gaitero y los vinos tintos Marqués de Riscal, en el sector de las bebidas. Dentro del sector de la cosmética destacan el perfume Ozonopino Ruy-Ram, la colonia Cecyl, el regenerador Royal Windsor y el Petróleo Gal. En cuanto a la publicidad de establecimientos aparecen con frecuencia los calzados Eureka, la joyería de Pérez Molina, la fábrica peletería del Carmen y los impermeables ingleses Linoleum, de venta en la Casa Maximino de Lope. También se incluye publicidad de otros sectores, como la Enciclopedia Espasa, las pastillas Doctor Andreu, la pasta dental Licor del Polo y el Callicida Escriba, por citar algunos ejemplos.

La presencia de anuncios en Blanco y Negro se hizo esperar algo más, comenzando a publicarse de forma habitual a partir de 1905. En un primer momento aparecen localizados en las últimas páginas, pero van ganando terreno hasta llegar a ocupar espacios destacados entre las primeras páginas. El volumen de anuncios superaba los cuarenta, reservando hasta seis páginas de cada número para la inserción de los mismos. Entre las marcas con mayor presencia en Blanco y Negro se encontraban el elixir estomacal de Saiz de Carlos, la emulsión Scott, las Pilules Orientales y los emplastos Allock, en el sector farmacéutico. Dentro del sector de la perfumería destacan la Crême Simon y la tintura para el cabello La Flor de Oro. También figuran con mucha frecuencia el Té Lipton, las mermeladas 
Trevijano, los relojes Carlos Coppel, las cámaras fotográficas Kodak y los prismáticos Zeiss.

En el caso de la revista Nuevo Mundo la publicidad aparece ya en el primer número publicado en enero de 1895 y se encuentra localizada en la última página de la publicación, siendo los primeros anunciantes el Servicio de la Compañía Trasatlántica de Barcelona, la Compañía de Navegación La Flecha, la fábrica de cigarrillos de Prudencio Rabell, la fábrica de barnices Francisco S. González, los vinos tintos de las bodegas de El Ciego y los vinos Estefani. Otros productos comúnmente anunciados eran las aguas Carabaña, la colonia Varón Dandy, el remedio para la calvicie Brotanil Sevilla, las máquinas de coser Singer, la Emulsión Scott, la pomada Baume Bengué para la gota y las pastillas del Dr. Andreu. La inserción de un anuncio telegráfico costaba una peseta y el precio por línea en la sección general variaba en función del número de inserciones. Más caros eran los reclamos publicitarios y los anuncios en el texto, costando 1,50 pesetas los primeros y 2,50 pesetas los segundos. Años más tarde los anuncios telegráficos doblarán su precio, costando en 1900 dos pesetas por quince palabras y o veinte céntimos más por cada nueva palabra ${ }^{5}$.

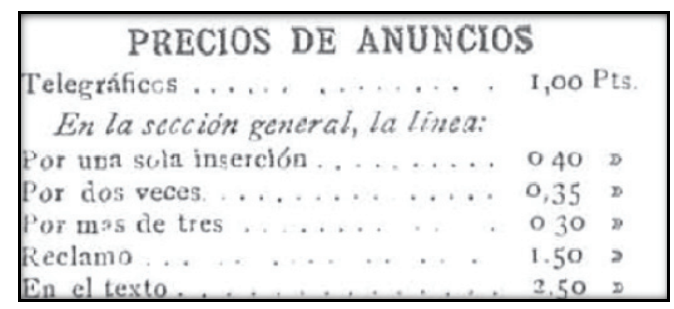

Fig.1. Precio de los anuncios en Nuevo Mundo (12/01/1898)

En Mundo Gráfico, al igual que en Nuevo Mundo, la publicidad está presente desde el primer número, publicado en 1911, pero con mayor volumen que en las anteriores. En el primer número se registran treinta y ocho anuncios distribuidos en diez de las treinta y cinco páginas totales. Muchos de los productos anunciados coinciden con las revistas ya mencionadas, aunque también encontramos algunos novedosos: Vincitor contra la calvicie y las canas, el Real Sanatorio de Guadarrama, el Foie Gras Siberia, las lociones Peele, las Conservas Trevijano, la fábrica de relojes de Carlos Coppel, las pastillas Valda y la Perfumería Floralia, por mencionar algunos de los más frecuentes.

Los sectores que lideran este despertar de la industria publicitaria fueron los productos farmacéuticos. La salud es uno de los bienes más preciados por la población del momento, afectada por epidemias, hambrunas y guerras. Esto justifica el predominio de la publicidad de medicamentos, que según Fernández

5 También los anuncios telegráficos de Mundo Gráfico tenían estos mismos costes desde el año 1911. 
Poyatos (2011:115) obedece a dos causas. Por un lado, desde finales del siglo XIX empiezan a desarrollarse nuevas técnicas y fórmulas químicas que permiten aumentar la esperanza de vida, que se situaba por aquel entonces en una edad media de cuarenta años. Por otro, la fuerte competencia del sector hace que para garantizarse un puesto en el mercado sea necesario diferenciarse del resto, convirtiendo la publicidad en el principal medio de promoción.

Superada la preocupación de la sociedad por la salud -que entraña una mejora de la calidad de vida- se despierta el interés por los hábitos higienistas, el cuidado personal y los productos cosméticos, que también se verá reflejado en la publicidad. En la década de los años veinte y treinta comenzarán a despegar otros sectores como la automoción, la alimentación y los artículos para el hogar. Será en este periodo cuando el mercado publicitario español empieza a dar muestras de una creciente complejidad. Las marcas adquieren un claro protagonismo y se diversifica la gama de productos ofertados. Los anuncios, hasta entonces constituidos por un breve texto con simples variaciones tipográficas, empiezan a incorporar ilustraciones acompañadas de eslóganes y mensajes mucho más estudiados y persuasivos.

\section{LAS PRIMERAS AGENCIAS PUBLICITARIAS}

En las últimas décadas del siglo XIX, algunos fabricantes comenzaron a apoyarse en profesionales para lanzar sus campañas publicitarias. Así surgieron los productos con marca propia que poco a poco fueron consiguiendo afianzarse en el mercado gracias a la publicidad. Entre estos se encontraban la Perfumería Gal, el Anís del Mono, las galletas María de Artiach y los vinos espumosos Codorniú y Freixenet. Es en esta época cuando surgen las primeras agencias publicitarias que comienzan actuando como mediadoras entre anunciantes y medios y con el tiempo llegan a encargarse por completo de la gestión de la comunicación de los anunciantes.

Según Fernández Poyatos (2010:58) a principios del siglo XX las principales agencias publicitarias establecían las sedes en Madrid y en Barcelona, ciudades que gozaban de un mayor impulso empresarial y por tanto ofrecían un panorama propicio para el desarrollo de su actividad. Después, iban abriendo sucursales allí donde aumentaban sus anunciantes, principalmente en ciudades como Bilbao, Sevilla y Valencia. La primera agencia española fue Sociedad General de Anuncios de España fundada en Madrid en 1853 a la que siguieron las agencias de Roldós y Valeriano Pérez, en 1870 y 1891 respectivamente (García Ruescas, 2000: 195). Otras importantes agencias publicitarias fundadas en años posteriores son Helios (1918), Publicitas (1922) y Veritas (1928), todas ellas con sede en Madrid ${ }^{6}$.

${ }^{6}$ Con la crisis de los años treinta y el posterior estallido de la Guerra Civil muchas de estas agencias verían interrumpida su actividad y otras acabaron desapareciendo. 
También las agencias utilizaron la prensa como principal medio publicitario de su actividad y servicios. Así por ejemplo, la primera agencia publicitaria anunciada en La Esfera fue la agencia francesa Havas ${ }^{7}$. De esta manera, con la prensa como aliada y las agencias como principales responsables de la elaboración de las campañas, la publicidad va ganando terreno en el primer tercio del siglo XX e incluso surgen una serie de publicaciones cuyo contenido era esencialmente publicitario, como La Gaceta Anunciadora (1902), Éxito (1919), Pompas de Jabón ${ }^{8}$ (1927), Propaganda (1928) y Publicidad y Ventas (1935).

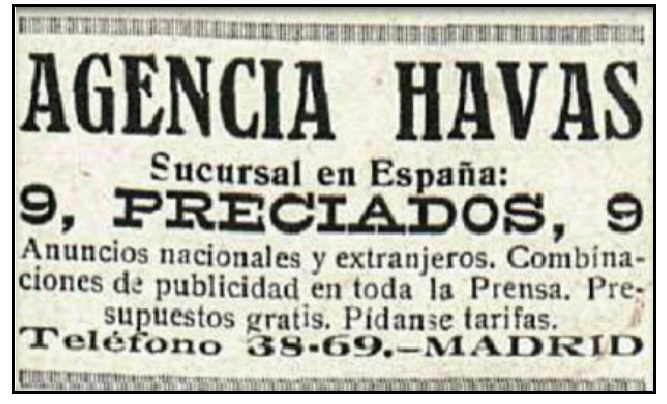

Fig. 2. Anuncio publicado en La Esfera el 10 de marzo de 1917

\section{LA ACTIVIDAd PUBLICITARIA EN La Esfera. ANÁliSiS POR SECTORES}

Perteneciente a la editorial Prensa Gráfica, La Esfera. Ilustración Mundial comenzó a publicarse en enero de 1914 y permaneció activa hasta enero de 1931. Bajo la dirección de Francisco Verdugo Landi y con Mariano Zavala como gerente, la revista se publicaba todos los sábados al precio de cincuenta céntimos. Presenta un formato novedoso de $27,5 \times 36,5 \mathrm{~cm}$ frente a las revistas ilustradas predecesoras cuyo formato habitual era de $18 \times 24 \mathrm{~cm}$. Sin embargo éste no fue el único aspecto clave para lograr captar la atención de los lectores, el principal reclamo fueron sus portadas ilustradas, siempre impresas en color y con cuidadas obras artísticas y fotografías. Se llegaron a publicar un total de 889 números, sin contar los extras conmemorativos de aniversarios y varios especiales dedicados a ciudades españolas.

De extensión variable, el número de páginas de La Esfera solía oscilar entre 31 y 35 páginas, aunque los números especiales editados a comienzo de año podían llegar a las 70 páginas.

7 Esta agencia se encargó desde 1920 de gestionar la publicidad de productos extranjeros en las revistas La Esfera y Mundo Gráfico.

${ }^{8}$ Publicación elaborada por la Perfumería Gal para la difusión y venta de sus productos. 
La Esfera puede considerarse un importante exponente de la publicidad de las tres primeras décadas del siglo XX en España. La inserción de anuncios fue una constante, desde el primer número de 1914 hasta el último en 1931, recogiendo en sus páginas los reclamos publicitarios de los productos, servicios y marcas que han dado respuesta a las necesidades y gustos de la sociedad de la época.

El análisis cuantitativo del volumen de anuncios publicados por la revista entre 1914 y 1931 -un total de 20.300- arroja como primer dato que los sectores con más presencia publicitaria son el editorial, con un $24 \%$, la salud (17\%) y la perfumería y cosmética $(16 \%)$ seguidos de lejos por los sectores de la fotografía (7\%), alimentación (6\%) y el sector textil $(5 \%)$. A continuación pasamos a comentar los datos y características de cada uno de ellos.

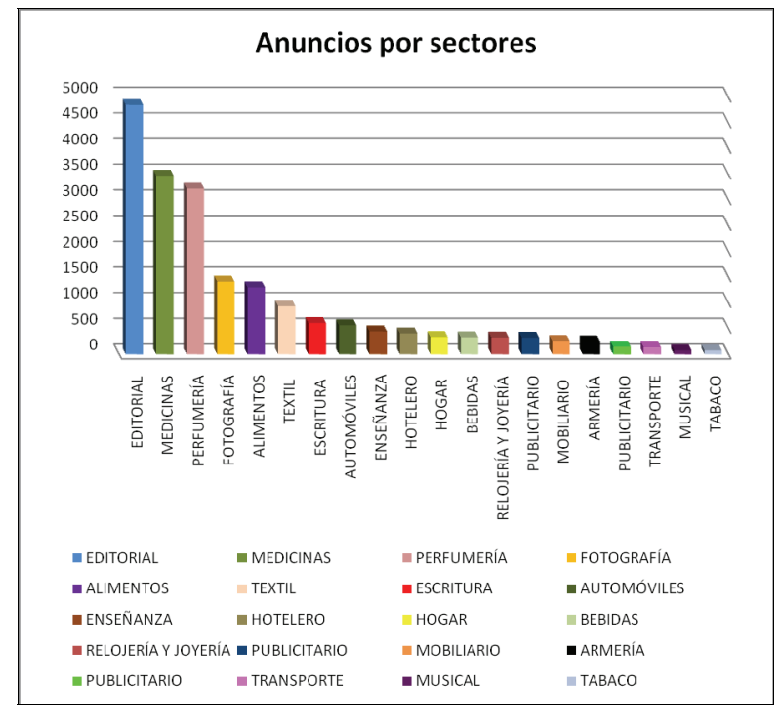

Gráfico 1. Número de anuncios publicados en La Esfera por sectores productivos

\subsection{Sector editorial}

Con un $24 \%$ este sector se sitúa a la cabeza de la publicidad en La Esfera. La razón que justifica esta posición destacada es que la propia editorial -Prensa Gráfica, S.A.- utilizaba estos espacios publicitarios para la promoción de sus otras publicaciones, como las revistas Nuevo Mundo, Mundo Gráfico, Por esos mundos y Elegancias así como para la difusión de obras literarias de autores como El Caballero Audaz, Dionisio Pérez y Emilio Carrere. También era frecuente encontrar publicidad de Papelera Española -fabricante del papel de la editorial- y de la librería San Martín, establecimiento de referencia para la contratación de 
espacios publicitarios y el abono de las suscripciones de las revistas de Prensa Gráfica ${ }^{9}$. También encontramos anuncios de otras casas editoras como la editorial Espasa Calpe, que con anuncios a página completa daba a conocer sus novedosas enciclopedias

Fig. 3. Anuncios de productos del sector editorial localizados en La Esfera en 1919 y 1924
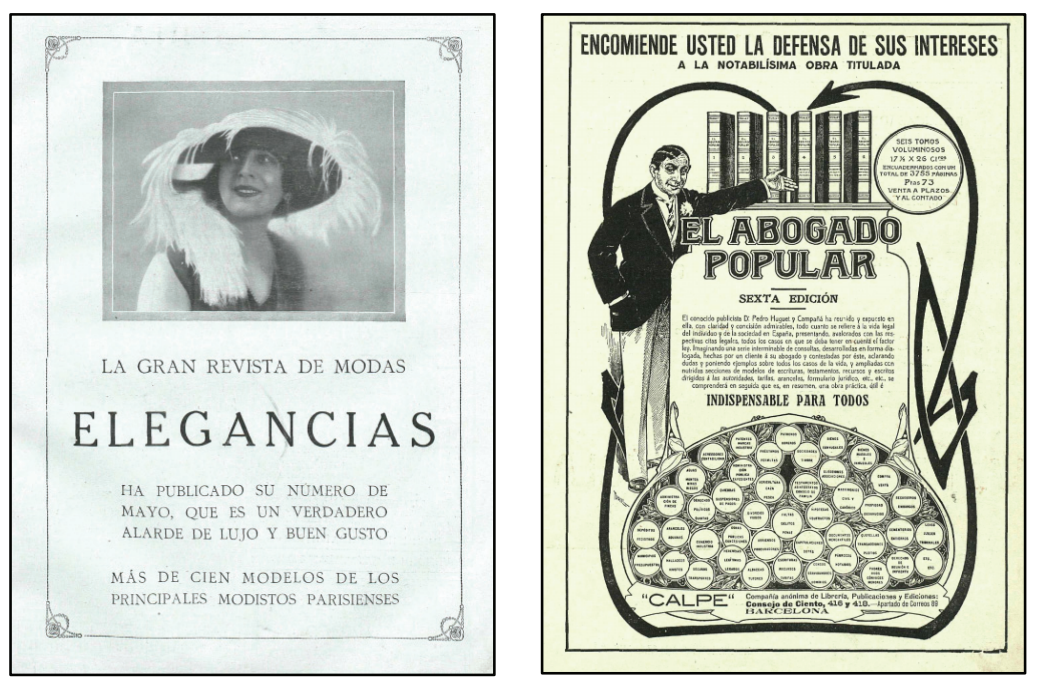

${ }^{9}$ Es posible que la editorial aprovechara los espacios vacantes para insertar sus anuncios en sus propias publicaciones o que esto respondiera a un motivo estratégico, ya que de esta manera, la editorial se aseguraba de tener una publicidad constante en los medios con más difusión de la época a coste cero. 


\subsection{Sector farmacéutico}

El aumento de productos medicinales en esta época no es de extrañar si tenemos en cuenta que en esos años la población debía hacer frente a incontables males: epidemias, mala alimentación, guerras, ignorancia en cuanto a métodos higiénicos y saludables. En definitiva, se trataba de una sociedad altamente deficitaria en salud, y por eso, se buscaban incesantemente nuevas formas y métodos para combatir las dolencias y enfermedades que acechaban a la población del momento. Así este sector supone un $17 \%$ del total de los anuncios. Esto justifica la proliferación de productos y ungüentos para remediar todo tipo de dolencias y su consiguiente reflejo en la publicidad. Entre los productos más anunciados destacan el Elixir Estomacal Saiz de Carlos; la pomada Baume Bengué para combatir la gota y los reumatismos; Siroline Roche para las afecciones pulmonares; las pastillas del Dr. Andreu y las pastillas Valda para la tos; el tónico Vino Vial para la debilidad de enfermos, ancianos y niños; las tabletas Bayern de Aspirina para los dolores de cabeza; para el estreñimiento se anunciaban marcas como Laxen Busto y la fruta laxante Tamar Indien Grillon. Mención especial merecen una serie de productos milagrosos de dudosa efectividad, que ponen de manifiesto la importancia que ya se confería a principios del siglo pasado al cuidado del aspecto físico. Sirva de ejemplo el Crecedor Racional de talla del Profesor Alberti Pi y Margall que se anunciaba con el siguiente texto: “¿Quiere usted crecer 8 centímetros? Lo conseguirá pronto, a cualquier edad, con el grandioso Crecedor Racional." Aunque el anuncio no especificaba el procedimiento empleado para lograr este aumento de estatura, aseguraba ser de lo más eficaz.

Entre los productos que pretendían ayudar a mantener la línea destacó por su frecuencia de aparición en la revista el tónico Delgadose Pesqui que aseguraba ser "el mejor remedio para adelgazar" ayudando a la "desaparición de la gordura superflua". Resultados similares ofrecía el Punkt-Roller, invento alemán con forma de rodillo de amasar, que según el propio anuncio "facilita por medio de una ligera pero penetrante succión, la circulación natural sanguinea de las partes grasas". Dirigidos específicamente al público femenino, eran los anuncios de las píldoras Pilules Orientales y las Píldoras Circasianas, que garantizaban el crecimiento y endurecimiento del pecho y el tratamiento Rohegel que aseguraba la cura de la esterilidad femenina. Para la impotencia masculina también se ofrecían remedios como las píldoras Herial y un aparato llamado Virility, cuyas aplicaciones y métodos no se explican en el anuncio. No menos curioso resulta el llamado Electro Mart, una especie de cinturón que mediante la aplicación de electricidad garantizaba curar dolores de estómago y restablecer el equilibrio nervioso.

En general, estos anuncios se caracterizaban por la brevedad de los mensajes y el empleo de sencillas ilustraciones de escasa calidad, que explicaban de un modo gráfico el modo de empleo y aplicación de los productos. De mayor calidad y complejidad fueron los anuncios de dos marcas: los Hipofosfitos Salud, jarabe 
reconstituyente para los casos de anemia y debilidad; y la Embrocación Española Gil, un lubrificante para mitigar los efectos del cansancio muscular.

Fig. 4. Anuncios de productos del sector farmacéutico publicados en La Esfera en 1917 y en 1920

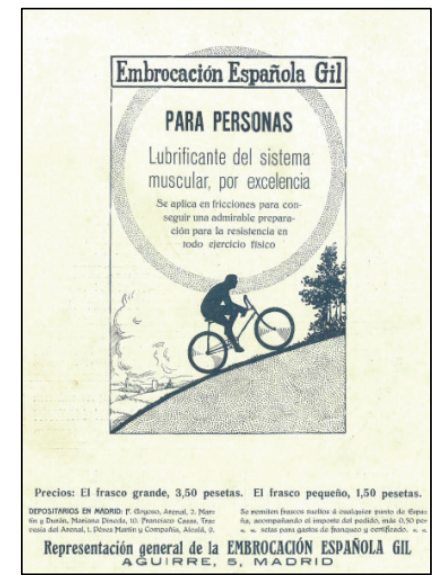

\subsection{Perfumería y cosmética}

Con un 17\%, es el tercer sector con mayor presencia publicitaria en La Esfera. Conviene señalar que, en general, los productos del sector cosmético se dirigían en su inmensa mayoría a las clases sociales altas, o lo que muchos anuncios denominaban como "gente chic". No obstante muchas marcas trataron de ampliar el mercado buscando nuevos consumidores en el ámbito rural. Con este propósito, algunas marcas inspiraron sus fragancias en aromas propios del campo, como hizo Gal con el jabón Heno de Pravia y la perfumería santanderina La Rosario con el jabón Aromas de la tierruca.

Casi el total de los productos de perfumería y cosmética anunciados en esta época estaban dirigidos al público femenino, exceptuando aquellos productos de uso específico masculino, como los referentes al afeitado de la barba (cremas, jabones, cuchillas y maquinillas), aunque con frecuencia los mensajes de estos anuncios se dirigían a las mujeres, ya que eran las encargadas de la selección y adquisición de estos productos para sus esposos. Igualmente, puesto que en esta época la mujer era la responsable principal del hogar y del cuidado de la familia, también los cuidados higiénicos durante la infancia se utilizaron como reclamo para la venta de jabones, lociones, talcos y otros productos para la higiene corporal de los niños. Así, se instaba a las madres a adquirir productos de ciertas marcas que aseguraban tener propiedades específicas para el tratamiento de las sensibles pieles de los bebés, como el jabón de la marca Pear's, o el dentífrico Colgate's que contribuyó con su publicidad a imponer el hábito de la higiene dental desde edades tempranas. 
Por su parte los productos cosméticos de maquillaje se dirigen ya a una mujer no sólo preocupada por atender a su familia, sino también por su aspecto y cuidado físico. Una mujer con una vida social más activa, que acude a eventos culturales y fiestas sociales, que busca la distinción y la elegancia. Así nos encontramos ya numerosos anuncios de polvos y cremas faciales que aseguraban preservar la juventud del cutis combatiendo arrugas e imperfecciones, y los coloretes y máscaras de pestañas para una imagen más sofisticada. La mayor parte de estos productos se importaban de Francia, aunque también hubo marcas españolas que se dedicaron a la producción de maquillajes, como Peele, Floralia, Gal, Peca Cura, Fisán y Myrurgia. En este sentido se tomó el modelo francés como el prototipo ideal de producto cosmético, por eso no es de extrañar que casi la mitad de las marcas de cosméticos anunciadas a principios del siglo $\mathrm{XX}$ fueran de procedencia francesa, y más concretamente, de París, capital de la moda durante los años veinte. Será en la capital francesa donde se imponga una nueva estética femenina que posteriormente imitarán otros países europeos y cuyo reflejo quedará patente en la publicidad de perfumes y cosméticos de nuestro país. De esta manera, en los años veinte nos encontramos ya con ilustraciones en las que las mujeres han sustituido las largas melenas por cortes de pelo a lo garçon, la silueta se vuelve más desenfadada y cómoda, de los ceñidos corsés se pasa a prendas con un corte recto de cintura baja. Este moderno look se completaba con variados accesorios como guantes, sombreros y cinturones.

Fig. 5. Anuncios del sector de la Perfumería Gal publicados en La Esfera en 1917 y 1930
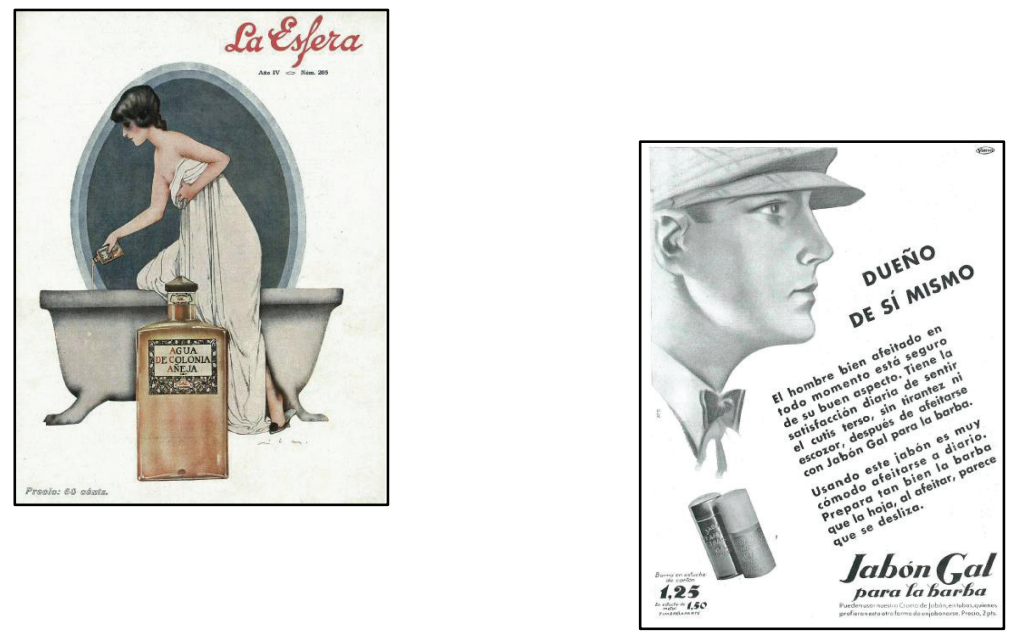

Pero el comercio de productos cosméticos no se limitó únicamente al sector femenino, sino que también el público masculino aparecerá reflejado 
esporádicamente en la publicidad. Ejemplo de ello son los anuncios de champús y lociones anticaída como el Regenerador Paz, la loción Lavona y Brotanil Sevilla. También los fijadores capilares como Fixor de la casa Gal. Los protagonistas de estos anuncios son hombres jóvenes y elegantes, de clase alta, que aparecen cortejando a mujeres en bailes y fiestas, practicando deportes como el golf o el tenis y conduciendo modernos automóviles.

\subsection{Sector alimentación}

Representa un 6\% de los anuncios publicados en La Esfera, siendo Trevijano y Siberia las marcas con mayor presencia en este sector. De la primera se anunciaron mermeladas y conservas y de la segunda salchichón, foie gras y mortadela. Otros productos frecuentemente anunciados fueron los chicles Wrigleys, la sopa Gourmet, las sardinas finas Ansola, el caldo Maggi, la salsa picante Lea \& Perrins, la carne de membrillo Justo Estrada, la harina lacteada y la leche condensada La Lechera ambas de Nestlé, los dátiles de la marca El Monaguillo y el completo Nesfarina, alimento fosfatado especialmente preparado para la nutrición infantil.

En los anuncios de este sector la mujer solía ser la protagonista de las ilustraciones. Abundan las escenas domésticas y familiares donde las mujeres aparecen representadas como amas de casa, preocupadas por la alimentación de sus hijos. Por la calidad de los anuncios destacaron las marcas Siberia, Nestlé y El Monaguillo.

Fig. 6. Anuncios de la marca Siberia y La Lechera publicados en La Esfera en 1926 y 1927
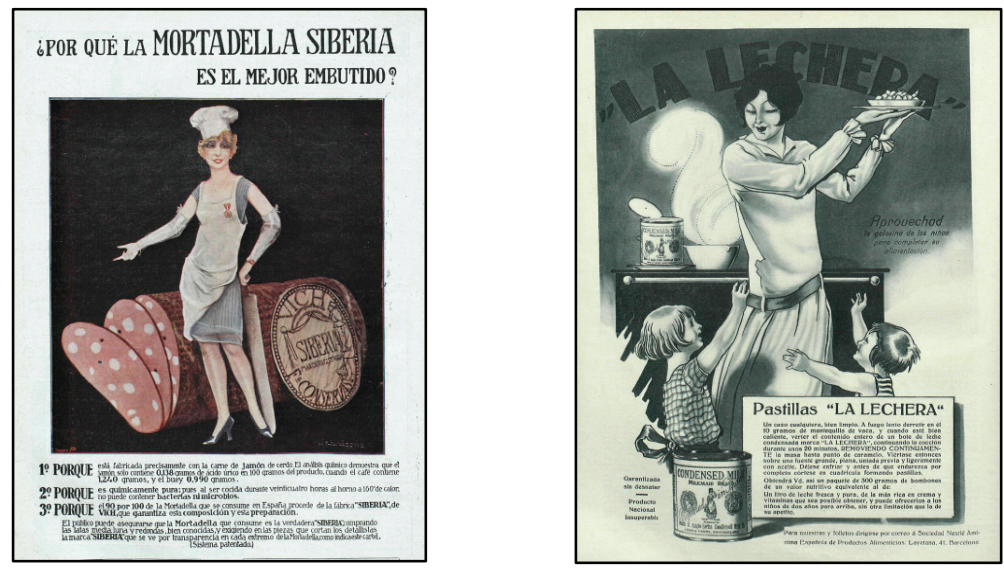


\subsection{Imagen y fotografía}

Este sector representa un $7 \%$ del total. Encontramos fundamentalmente anuncios de estudios de fotografía y cámaras fotográficas de distintas marcas. Entre los primeros se encuentran muchos de los fotógrafos más destacados de principios del siglo XX, como Kaulak, Biedma, Alfonso, Walken, Compañy, Calvache y Díaz Casariego. Se trataba de anuncios sencillos y breves en los que únicamente figuraba el nombre y dirección del establecimiento en cuestión. Por su parte, la primera cámara de fotos anunciada en La Esfera fue la cámara Klapp de la marca Ernemann, cuyo anuncio apareció publicado en 1914. Los anuncios de las cámaras fotográficas Kodak aparecen en 1921, especialmente durante los meses estivales, para animar a preservar los buenos recuerdos de las vacaciones de verano.

Fig. 7. Anuncios del estudio fotográfico de Biedma y de las cámaras de fotos Kodak publicados en La Esfera en 1927
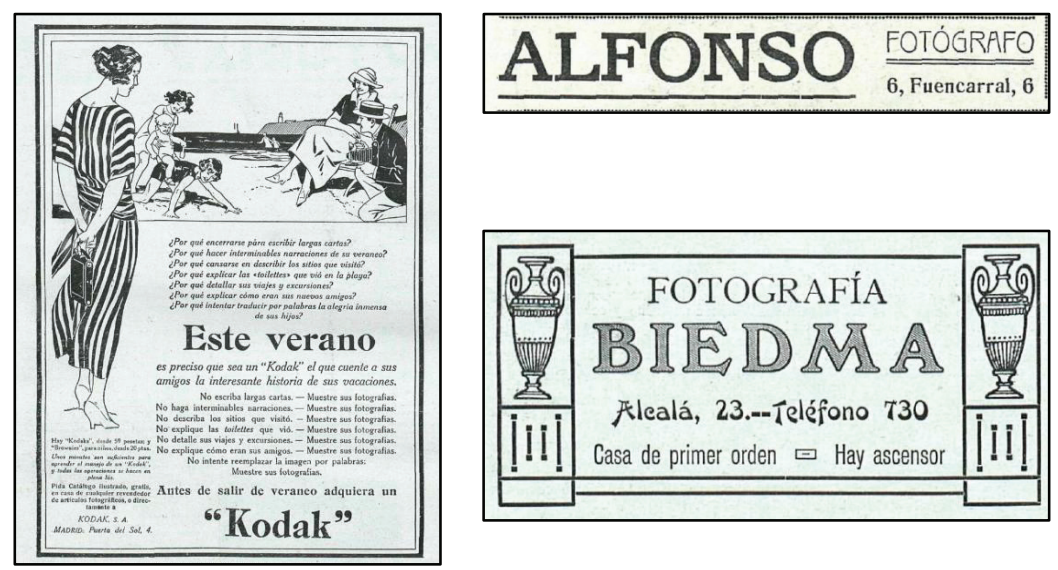

\subsection{Sector textil}

Con un 5\%, este sector permite establecer una distinción muy clara entre los anuncios de establecimientos y los de productos de firmas y marcas concretas. En el primer grupo se encuentran la peletería Arturo Ventura y Vázquez, las camiserías Roldán y Antisenty, la casa de modas Lacoma y la sombrerería Carmen de Pablo. El contenido de estos anuncios era principalmente la dirección de los comercios y una breve descripción de la gama de productos que ofrecían. Al segundo grupo pertenecen los anuncios de los calcetines Molfort's, los cuellos 
Suplex, los bolsos Luis Vuitton, los pañuelos Kotex, el "sostenedor" de pecho Hautana, los trajes interiores de punto Vigor, Dr. Rasurel, Dr. Robber que aseguraban ser esenciales "para conservar la salud y el vigor". También los calzados Eureka y La Imperial, y las suelas de zapato Philips Rubbers.

Fig. 8. Anuncios del sector textil publicados en La Esfera en 1921 y 1927 respectivamente
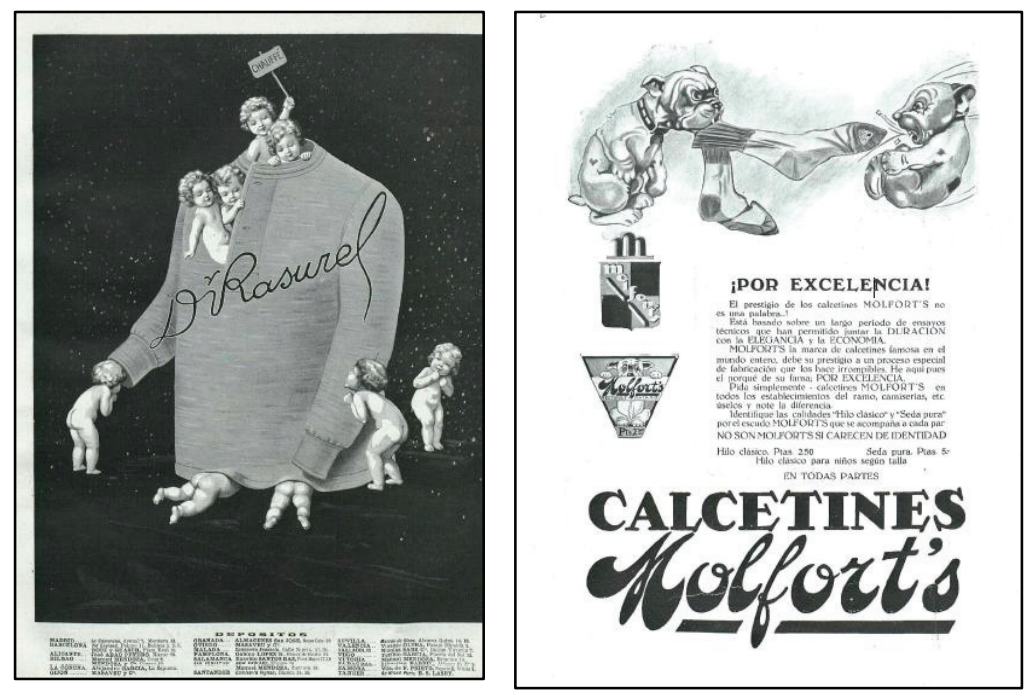

\subsection{El sector de la escritura y mecanografía}

Constituye el 3\% del total de los anuncios publicados en La Esfera y en la mayoría de los casos se trata de anuncios cortos y sencillos, con pequeñas ilustraciones de los productos anunciados, especialmente en el caso de las máquinas de escribir. Los productos más anunciados son las plumas, de las que se ofertan varias marcas: Cervantes $n^{\circ} 2$, Waterman, Wahl, Onoto, Tempoint y Sheaffer's. También comienzan a anunciarse en 1930 los lápices Castell y los botes de tinta, de las marcas Pedro Closas y Sama. Además en estos años se lanzarán a mercado publicitario varios modelos de máquinas de escribir, desde las míticas Underwood, hasta de otras marcas como Corona, Continental, Remington y Smith Premier. 
Fig. 9. Anuncios de la pluma estilográfica Wahl y de la máquinas de escribir Remington
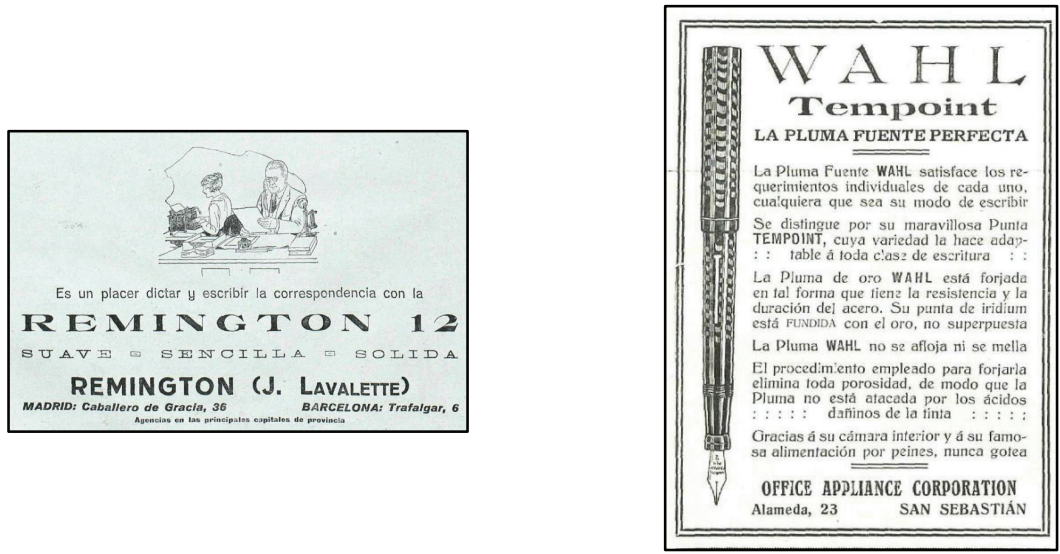

\subsection{El sector automoción}

En este sector, con una presencia del 3\%, se registran anuncios más elaborados, con numerosas ilustraciones de gran calidad, muchas de ellas a color. El primer anuncio en color publicado en La Esfera fue de Renault, en 1914. Otras marcas de vehículos anunciadas fueron Maxwekk, Humber, Ford, Benz Luxusmagen y Mercedes. Les siguen en años posteriores los automóviles Rocca, Overland, Citroën, Packard, Dobi, Th. Schneider, Crossley, Cadillac, Chrysler, Auburn, Lincoln, Hudson \& Essex, Overlando Whippet, Dunlop, Graham Paige y las motocicletas Indian. También se anunciaron marcas de neumáticos destacando Continental, United States, Firestone y Good Year.

En estos anuncios el principal elemento de interés es el automóvil, cuya ilustración suele ocupar la parte primordial del anuncio. Los acompañan hombres elegantemente vestidos, de clase social alta y porte elegante. Se ha observado que a finales de los años veinte este sector dirige ya parte de sus anuncios al público femenino, puesto que comienzan a aparecer también mujeres conduciendo modernos automóviles acompañadas de sus amigas. 
Fig.10. Anuncios de automóviles publicados en La Esfera en 1914 y 1928 respectivamente
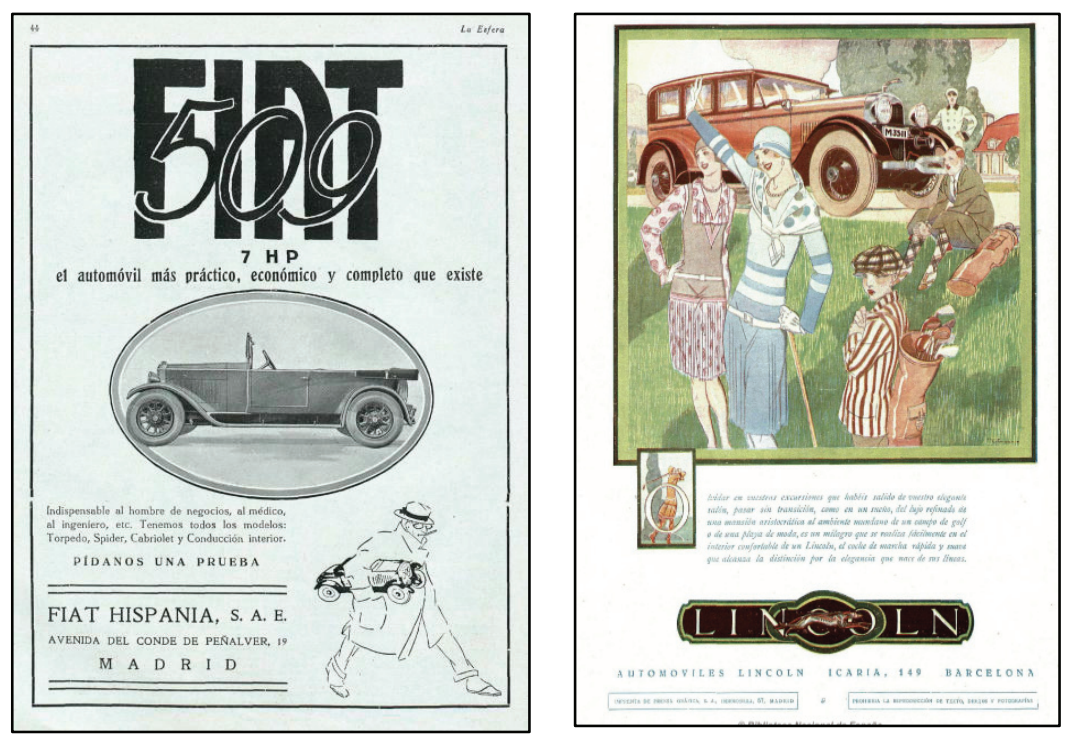

\subsection{El sector de la educación}

Representa un 2\% del total. Se trata de anuncios breves de carácter tipográfico en los que consta la dirección del centro educativo y los cursos de formación que se ofrecían. No se observa una gran variedad aunque las academias que se anunciaban lo hacían con frecuencia. Ejemplos son la Institución Cervera (dedicada a la enseñanza por correspondencia de electricidad, mecánica, ingeniería...) y la Escuela Berlitz cuyos anuncios aparecen a partir de 1920 de manera casi ininterrumpida. 
Fig.11. Anuncios del sector educativo publicados en La Esfera
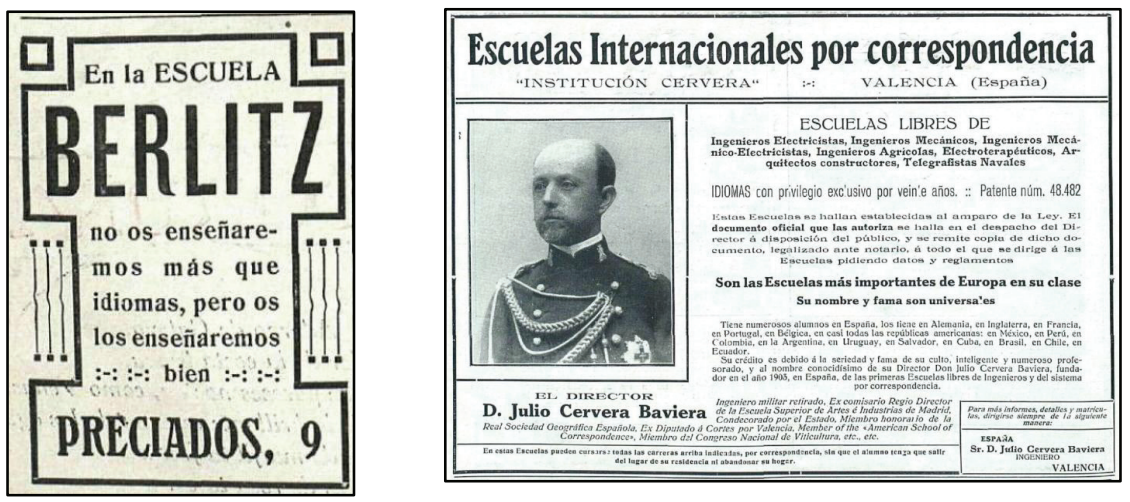

\subsection{El sector hotelero y de restauración}

Constituye el $2 \%$. Se trata de una publicidad de los establecimientos hoteleros de lujo de las principales capitales europeas, como los hoteles madrileños Ritz y Palace, el hotel Cecil de Londres y el Majestic de Barcelona. También se anunciaban frecuentemente balnearios como el de Marmolejo, el balneario de Baños de Monlemayor, La Aliseda, y el de Lierganes en Santander, entre muchos otros. Muchos de ellos aseguraban ser una cura eficaz para numerosas dolencias del estómago, hígado, e incluso de la anemia. Apenas nos encontramos ilustraciones, y cuando aparecen son meras representaciones de las fachadas de los edificios. 
Fig.12. Anuncios de hoteles y balnearios publicados en La Esfera
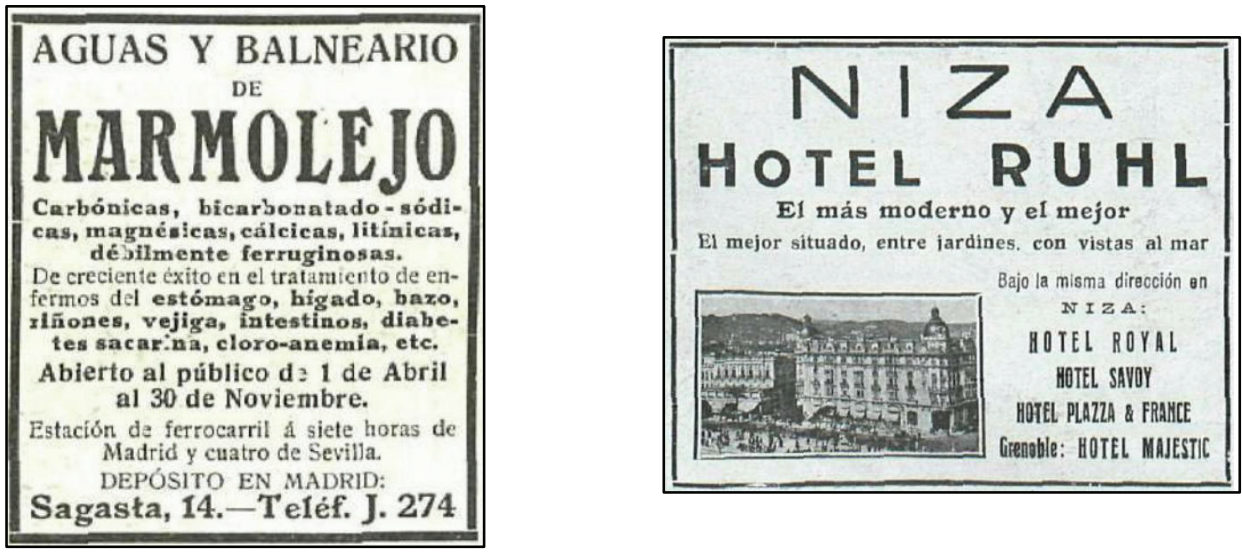

\subsection{El sector doméstico}

Este sector cuenta con una presencia publicitaria de un 2\%. Es muy amplio en cuanto a la variedad de productos anunciados. Así, para la limpieza del hogar, encontramos productos como VIM para azulejos y cristal, el desinfectante Lysoform, la crema Johnson para la madera, las mopas O-Cedar Mop, Bon Ami para la limpieza de espejos, el lavarropa Rinso; electrodomésticos, como las enceradoras y aspiradoras de la marca Electro Lux; lámparas y bombillas como las Philips Watt, las Nitra, las Metal Watt y otros para la seguridad del hogar como la cerraduras y picaportes The Yale \& Tone. Dirigidos siempre al público femenino, frecuentemente aparecen mujeres haciendo uso de los productos y también los mensajes se dirigen a ellas.

Por su originalidad artística merecen una mención especial los anuncios de las lámparas Metal de la Compañía General Española de Electricidad de cuya publicidad se encargó la agencia Helio. Conjugando fotografía e ilustración y con la mujer como elemento central de todos los anuncios, esta marca de bombillas otorgó ya en las primeras décadas del siglo XX una importancia primordial a la publicidad publicando anuncios a página completa en las revistas con mayor repercusión de la época. 
Fig.13. Anuncios publicados en La Esfera en 1920 y 1922
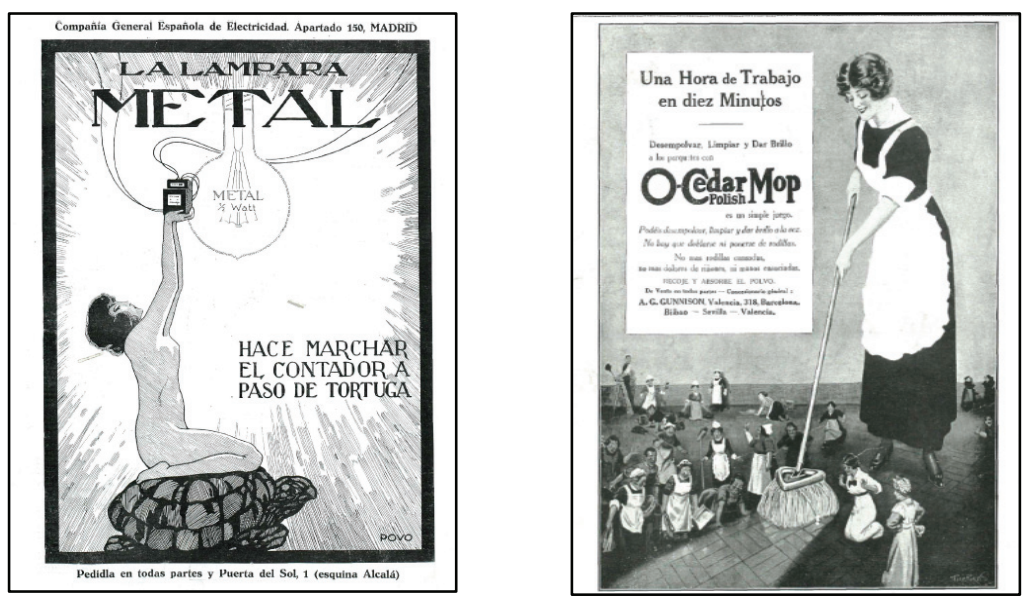

\subsection{Bebidas y licores}

Representa un $2 \%$, destacando especialmente los anuncios del coñac Caballero, aunque se anunciaron frecuencia otras bebidas y licores como el anís Ríos, el ron Negrita, el vermut Francisco Cinzano \& Cía, los vinos y coñacs Pemartín, Xerez-Quina Ruiz y el vino moscatel Hermanos López. También tés como la marca inglesa Endvar y Ratanpúro y aguas como Mondadoriz, Cabreiroá, Villaza, Peñagallo. Dentro de este sector destacaron por su presencia y calidad los anuncios de la marca Caballero cuyas ilustraciones suelen representar ambientes distendidos y festivos, reuniones sociales y celebraciones con la familia y amigos. 
Fig. 14. Anuncios publicados en La Esfera en 1921
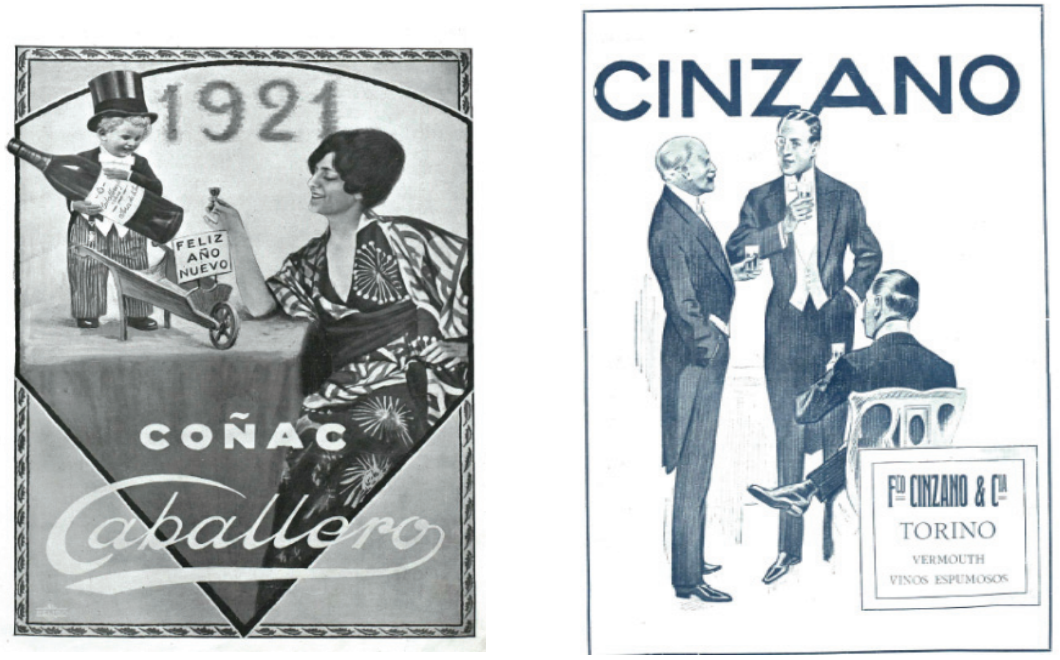

\subsection{Relojería y joyería}

Con una presencia de un $2 \%$ la publicidad de este sector está protagonizada principalmente por dos marcas: Trust Joyero y los relojes de Carlos Coppel. No obstante, aparecerán anuncios de otras muchas marcas, como los relojes de Ermeto Movado, la platería D. González, las perlas Kepta, la joyería L'Aduiza, los relojes Omega y las alhajas de Fernández y Veiga, aunque los anuncios de estas marcas eran mucho más sencillos y estaban formados básicamente por breves mensajes textuales.

Fig.15. Anuncios de relojes y joyas localizados en La Esfera en 1921 y en 1922
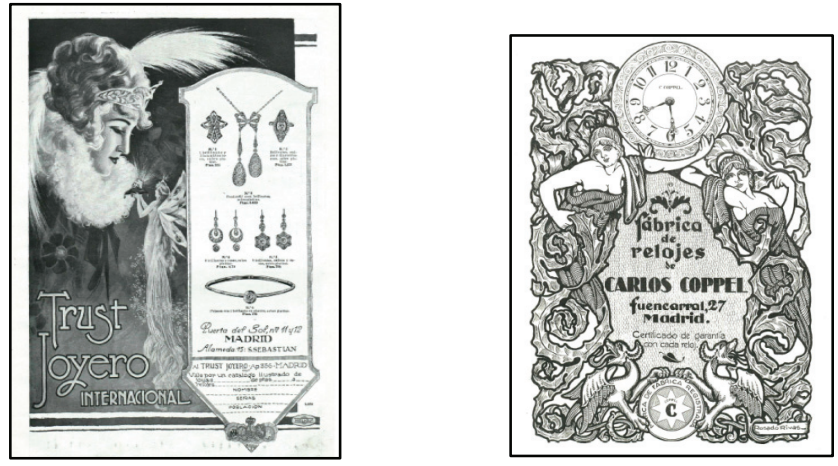


\subsection{El sector publicitario}

También el propio sector publicitario, con un $2 \%$, hizo uso de la prensa para publicar anuncios en los que ofertar sus servicios. En este sentido, la editorial Prensa Gráfica fue pionera en buscar en la publicidad el medio para financiar sus publicaciones.

Así se constata en anuncios localizados en La Esfera en 1916 en los que la editorial informa a los potenciales anunciantes de las bondades de la publicidad y les ofrece sus servicios para la difusión de sus anuncios. En uno de los anuncios, ilustrado por Federico Ribas, se trata de justificar la importancia del uso de la publicidad con un eslogan tan llamativo como "Los efectos de la guerra europea en el comercio pueden ser contrarrestados por la publicidad".

En otro de los anuncios se compara la publicidad en la empresa con el combustible en los trenes: "Las cuestas penosas se vencen a expensas del carbón. Esta máquina quedaría parada en medio de la pendiente que recorre, si el fogonero no atizara el hogar de la caldera echando combustible. Algo semejante ocurre con los negocios en este momento. Hay que echarles combustible para que puedan subir la penosa pendiente en que los ha colocado la guerra europea. Y para los negocios no hay más combustible que la publicidad, a condición de hacerla de modo sugestivo y en órganos que circulen. Anuncie usted su negocio para que le sea fácil vencer la empinada cuesta de su actual camino. (...) Eche carbón a su máquina. Anuncie usted.

Fig.16. Anuncios de Prensa Gráfica S.A. publicados en La Esfera en 1916
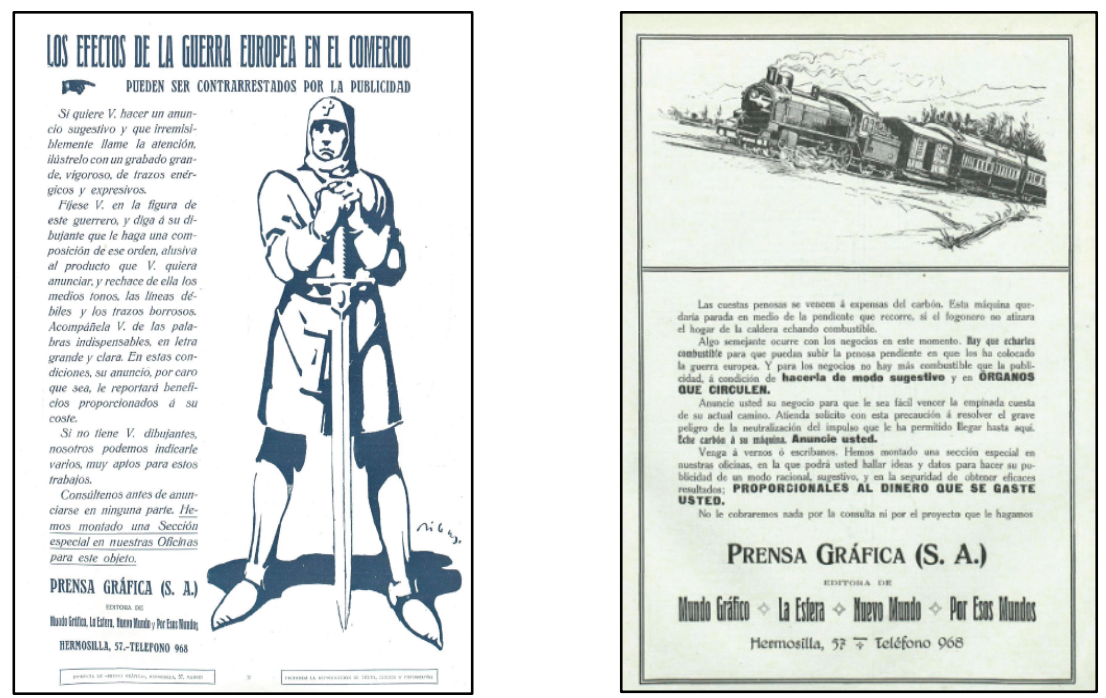
Años más tarde, se incorporarán al mercado publicitario las agencias, que también ofrecerán sus servicios a través de los anuncios. Es el caso de la agencia francesa Havas, en 1917 y Publicitas, en 1923. Esta última agrupa a la agencia Fama de Barcelona y Helios de Madrid y será la encargada de gestionar la publicidad en la revista que nos ocupa.

\subsection{El sector mobiliario}

En este sector se incluyen anuncios de establecimientos de venta de muebles de lujo como Santos Riesco, Janssen y la Casa Vilches y la orfebrería de arte Miele y Compañía, de objetos decorativos. Se trata de anuncios sencillos, meramente textuales en los que se indicaba la dirección de los establecimientos y los objetos que allí podían adquirirse.

Fig.17. Anuncios del sector mobiliario publicados en La Esfera
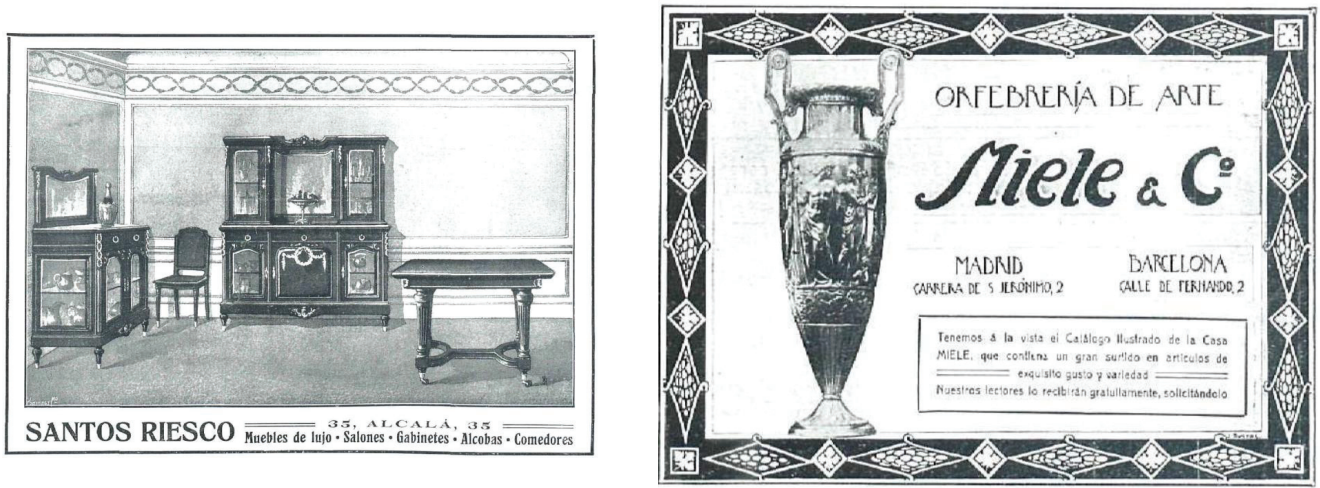

\subsection{Armería}

Las nuevas aficiones de las clases sociales emergentes justifican la presencia de este sector en el mercado publicitario, con un $1 \%$, en el que se anunciaron las escopetas Eiba, de Víctor Sarasqueta y las armas y municiones de la marca Remington. Se trataba de anuncios cortos con ilustraciones sencillas. 
Fig. 18. Anuncios de armas y cartuchos en La Esfera

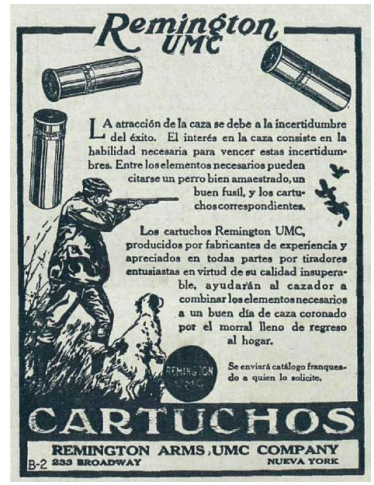

Escopetas finas de precisión y caza = PARA TIRO DE PICHON =

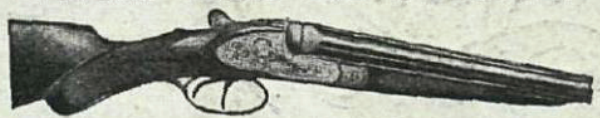

EI B A R. -Victor Sarasqueta Proveedor y labricante de S. M. el Rey Don Alfonso Xlll y de S. A. la Inlanta Doña lsabel

\subsection{Medios de transporte}

El progresivo desarrollo de los medios de transporte y el gusto y afición por los viajes promueve la publicidad de este sector $(1 \%)$, como los trenes rápidos para los baños en Alicante, la Compañía de Ferrocarriles de Madrid al oeste de España, los trenes de lujo Sud Expres y la Compañía Internacional de coches cama. También se anuncian viajes programados a Lucerna, Portugal y otros lugares dentro de España. Se trata de anuncios de carácter textual y con una función meramente informativa con menor interés desde el punto de vista artístico y de ilustración.

Fig. 19. Anuncios del sector publicados en La Esfera

La Compañia Internacional de Coches-Camas ha instalado en San Sebastian, Alameda, 14, una lujosa Agencia propia, habilitada para despachar los asientos de cama, billetes de ferrocarril, pasajes de navega-

Con la instalación de esta Agencia demuestra la Compañía citada que procura siempre atender slas exigencias de la distinguida clientela que utiliza sus carruajes, la que celebrará seguramente encontrar facilidades citadas son para el regreso de San Sebastián á Madrid.

\section{VIAJES DE EXCURSIÓN}

La Compañía de los ferrocarriles de Madrid ả Cáceres y Portugal y del Oeste de España acaba de publicar el servicio especial de excursiones para los darningos y días festivos desde Madrid-Delicias á las eslaciones comprendidas entre Villaverde y Talavera de la Reina, que desde hace siete años viene haciendo durante la temporada de verano con gran satisfacción del público.

El servicio del presente año empezará el domingo 16 de Mayo para terminer el $\widehat{z}$ de Octubre próximo y comprende también, además de los domingos, los días $\tilde{z}$ y 29 de Junio.

El primer día de excursión coincide este año con la gran feria de

Lalavera de la Reina.
Los pros de los billetes de ida y vuelta son, como en los años anteiores, de exirema baratura, y lanio dichos precios como el servicio de 


\subsection{Música y sonido}

Se incluyen tanto anuncios de instrumentos musicales, como el Pianola-Piano, como los reproductores de sonido de la época, la "máquina parlante" de la marca Homokord, los gramófonos Odeon y los discos Fadas. Los anuncios de estos productos venían acompañados de los establecimientos en los cuales podían adquirirse. Un aspecto llamativo es que no se anuncia únicamente un producto en concreto sino que se solían incluir menciones a otros productos también disponibles en los establecimientos de venta, por lo que podríamos decir que la publicidad de este sector no es de producto sino de punto de venta.

Fig. 20. Anuncios del sector publicados en La Esfera

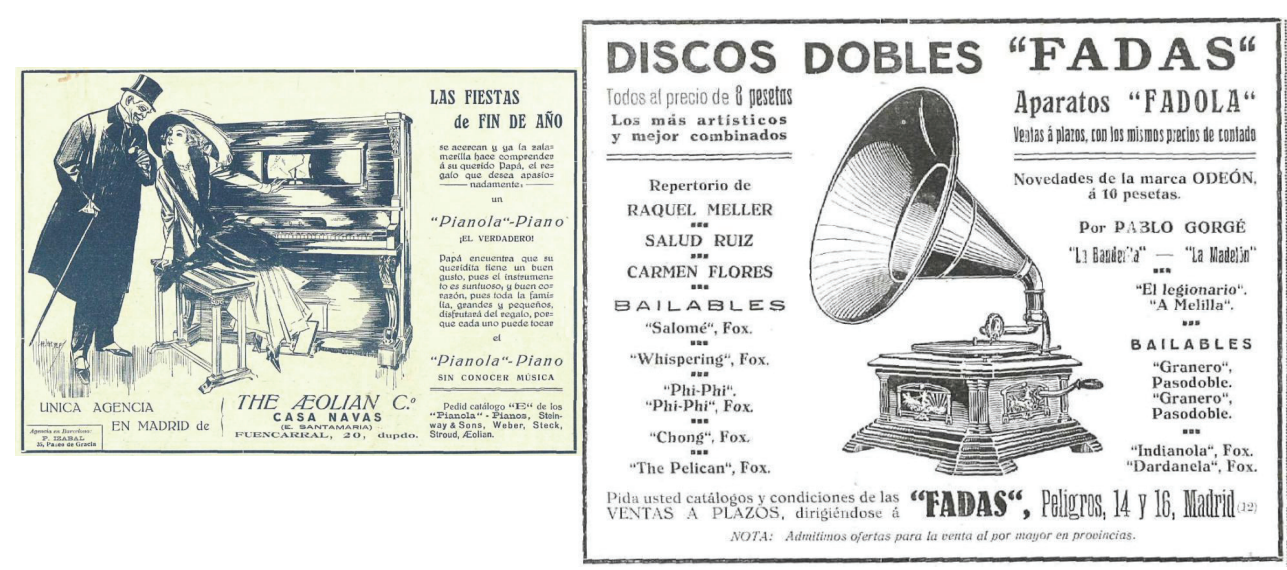

\subsection{El sector del tabaco}

Con un 1\% la publicidad de este sector responde a los nuevos gustos de las clases burguesas, que buscan la distinción y la sofisticación en el consumo de productos como los cigarrillos. Así lo refleja la publicidad, que a diferencia de otros sectores, es bastante más elaborada y con numerosas ilustraciones protagonizadas por sugerentes mujeres con trajes elegantes. Destacan marcas como Vittoria Egyptian Cygarette Company, Kalliston Cigarretes y Cigarrillos Orientales. 
Fig. 21. Anuncios publicados en La Esfera en 1921 y 1922
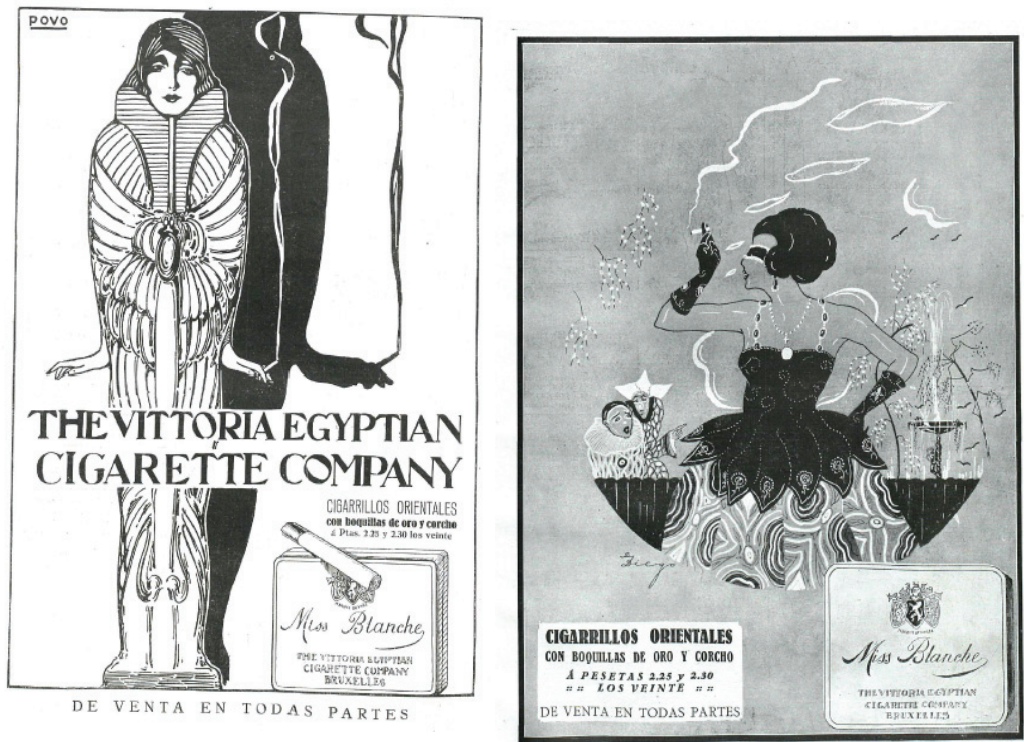

\section{CONCLUSIONES}

El estudio general de la actividad publicitaria de los distintos sectores en la prensa ilustrada permite señalar las siguientes conclusiones:

1) Con carácter general, se ha comprobado que los sectores con mayor presencia publicitaria eran el farmacéutico y el sector cosmético. Algunas marcas y productos fueron una constante en las publicaciones analizadas, como las pastillas Valda, los Hipofosfitos Salud y las pastillas para la tos del Dr. Andreu, en el sector de la salud. En el sector cosmético, además de los productos de la Perfumería Gal (en especial el Jabón Heno de Pravia), también destacan el Jabón Palmolive y los dentífricos Colgate. A partir de la primera década del siglo XX se incorporarán nuevos sectores y productos en la publicidad como las bombillas Metal, Egmar o Nitra; las cámaras fotográficas Kodak, los prismáticos Goerz y Zeiss, las máquinas de escribir Underwood, los cinematógrafos Kok, los gramófonos Homokord, las máquinas de coser Singer y los automóviles Fiat, Renault, Lincoln, Citröen, Chevrolet y Ford, por citar algunos ejemplos. 
2) En la década de los años veinte la presencia de anuncios y reclamos publicitarios experimenta un desarrollo considerable, apreciable en las revistas ilustradas de la época como La Esfera, Mundo Gráfico, Nuevo Mundo y Blanco y Negro. Existe una relación directa entre el crecimiento del número de publicaciones y el incremento de inserciones publicitarias en las mismas. Por tanto, se puede decir que hay una relación directa en el desarrollo de ambos medios.

3) Entre las publicaciones de la editora Prensa Gráfica Nuevo Mundo, Mundo Gráfico y La Esfera, existen una serie de similitudes en el tratamiento de la publicidad, concretamente, el número de páginas destinadas a este fin, el número de anuncios incluidos y la localización de éstos dentro de la publicación, observación que ha permitido identificar dos etapas. La primera, entre 1900-1912, en la que las inserciones publicitarias no superaban las ocho páginas en cada número, con un total de 20-30 anuncios y ninguno a toda página. La segunda entre 1913-1930, donde la publicidad es más abundante, llegando a superar la centena. Los elementos gráficos son cada vez más frecuentes y la ilustración se convierte en un elemento clave en la publicidad de las marcas. La localización de los anuncios también experimenta cambios, ocupando las páginas centrales e incluso compartiendo espacios con otras secciones. Desaparecen los anuncios telegráficos, y aumentan en cambio el número de marcas cuya publicidad ocupa la página completa. En este periodo también se publican anuncios disimulados con formato de artículo que ocupaban páginas completas ${ }^{10} \mathrm{y}$ que de esta manera se diferenciaban del resto y conseguían dotar de mayor credibilidad al mensaje publicitario.

4) Se confirma la importancia que la publicidad tiene en el éxito comercial de las marcas. Así se ha constatado al comprobar que muchas de las empresas que más invirtieron en publicidad en el siglo pasado lograron un gran reconocimiento y calado en la sociedad de la época que en algunos casos aún perdura, como ocurre con los productos de Colgate, La Toja y Palmolive, además de los automóviles Renault y Ford, los alimentos de Nestlé y el coñac Caballero, por citar algunos ejemplos. El valor otorgado a la publicidad por estas marcas se ve reflejado en la variada tipología de sus anuncios, la contratación de agencias dedicadas a la elaboración de sus campañas publicitarias, el empleo de mensajes publicitarios más complejos y persuasivos, así como la frecuencia de aparición de los mismos.

${ }^{10}$ En la mayoría de los casos se trataba de anuncios que ofrecían servicios y remedios curativos para las enfermedades y dolencias de la época, como la tisis y la tuberculosis. 
5) Durante el periodo estudiado, la técnica más empleada para el diseño de los anuncios es la ilustración, que se aplica en los anuncios de todos los sectores, y de forma destacada, en el sector cosmético. La técnica fotográfica se utiliza principalmente en la publicidad del sector automovilístico. En algunos casos se combina fotografía e ilustración, como ocurre en los anuncios del Petróleo Gal y de las lámparas Metal. Otro ejemplo será la marca cosmética Peele que empleará retratos fotográficos de artistas de la época para promocionar sus productos de belleza.

6) En publicidad una imagen vale más que mil palabras. La importancia que tiene una imagen es fundamental para captar la atención del público. Entre todos los sectores analizados, destaca por la abundancia de imágenes empleadas en publicidad el sector cosmético, donde el factor estético juega un papel primordial a la hora de atraer al público objetivo, que en esta época era fundamentalmente femenino.

7) Los anuncios de la casa Gal ocuparon un lugar preferente en la revista $L a$ Esfera, publicados siempre a página completa. La Perfumería Gal contaba con espacios reservados exclusivamente para la publicidad de su marca, que generalmente situaba en la primera o última página y que incluso llegaron a ocupar la portada de la revista desde 1916 hasta 1918.

8) Algunas marcas encargaron el diseño de sus anuncios a prestigiosos artistas de la época. Es el caso de la Perfumería Gal, pionera en la creación de un departamento de publicidad, a cuyo frente artístico estuvo Federico Ribas. Otras marcas que siguieron esta senda fueron Calber, con Baldrich ilustrando sus anuncios; la perfumería catalana Myrurgia cuyas ilustraciones fueron realizadas por Eduard Jener; y la Perfumería Floralia, que contó con la participación de numerosos artistas de la talla de Rafael Penagos, Bartolozzi, Varela de Seijas y Porta, por citar algunos ejemplos.

\section{REFERENCIAS BIBLIOGRÁFICAS}

ALDUNATE LEÓN, O; HEREDIA URDÁIZ, I (Coords). Actas del I Encuentro de Jóvenes Investigadores de la AHC. Zaragoza: Prensas Universitarias de Zaragoza, 2008.2 Disponible en: http://www.lahistoriadelapublicidad.com/documentos/anunciaresvender_2060 .pdf [Consulta: 22/12/2011]

ALVARADO LÓPEZ, M ${ }^{\text {a }}$ Cruz. Educar para vender: un caso emblemático de publicidad educativa y comercial en España de 1930. En: BERMEJO BERROS, J. (coord.). Publicidad y Cambio Social. Contribuciones históricas y perspectivas de futuro. Sevilla: Comunicación Social, 2005. 


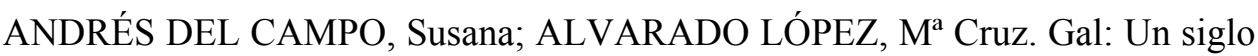
de perfumería, un siglo de publicidad. Publifilia. Revista de Culturas Publicitarias, 1998, $\mathrm{n}^{\circ}$ 1, p. 23-50.

ANDRÉS DEL CAMPO, Susana; ALVARADO LÓPEZ, Ma Cruz. Gal: un siglo de perfumería, un siglo de publicidad. La dimensión artística de la publicidad. Publifilia. Revista de Culturas Publicitarias, 1999, n² 2, p. 49-64.

BERNAL SANCHO, Maya. La conformación de la norma de consumo en España. Perfumería Gal. Disponible http://www.uned.es/125051/socicon/documentos/perfumeria_gal.pdf [Consulta: 22/12/2011]

CEBRIÁN GONZÁLEZ, Carlos. Historia de la publicidad. Tomo 1, 1900-1950. Zaragoza: Delsán, 2007.

CHECA, Antonio. Historia de la publicidad. La Coruña: Netbiblo, 2007.

EGUIZÁBAL, Raúl. Historia de la publicidad. Madrid: Fragua, 2011.

FERNÁNDEZ MELLADO, Rebeca. El cartel de cine español de posguerra (1939-1945): Modelo de tratamiento documental. Cuadernos de Documentación Multimedia, $\mathrm{N}^{\mathrm{o}}$ 18, 2007. Disponible en: http://multidoc.rediris.es/cdm/viewarticle.php?id=57 [Consulta: 20/11/2011]

FERNÁNDEZ POYATOS, $\mathrm{M}^{\mathrm{a}}$ Dolores. Las primeras agencias españolas de publicidad: 1912-1934. Questiones Publicitarias, vol. I, no 15, 2010, p. 52-71.

FERNÁNDEZ POYATOS, $\mathrm{M}^{\mathrm{a}}$ Dolores. La publicidad de salud en la prensa ilustrada de finales del siglo XIX. Questiones Publicitarias, vol. I, $\mathrm{n}^{\mathrm{o}} 16$, 2011, p. 108-124.

GARCÍA RUESCAS, Francisco. Historia de la publicidad y del arte comercial en España: desde tiempos remotos, al final del siglo XX. Madrid: Aurus, 2000.

LOZANO BARTOLOZZI, $\mathrm{M}^{\mathrm{a}}$ Mar. Los carteles y el arte publicitario de Salvador Bartolozzi (1882-1950). Norba-arte, 1992, $\mathrm{n}^{\circ} 12$, p. 187-202. Disponible en: http://dialnet.unirioja.es/servlet/articulo?codigo $=107454$ [Consulta: 20/12/2011]

MARCOS-RECIO, J.C. Técnicas bibliográficas para el análisis documental en publicidad: una propuesta básica. En: ANDRÉS DEL CAMPO, S. (Coord.) Otros fines de la publicidad. Sevilla: Comunicación Social, Ediciones y Publicaciones, 2009.

PRAT GABALLÍ, Pedro. Publicidad Racional. Barcelona: Labor, 1934.

QUINTAS FROUFE, Eva. Origen y proliferación de los concursos de carteles a principios del siglo XX: El concurso de la Perfumería Gal (1916). Área abierta, $\mathrm{n}^{\mathrm{0}} 21,2008$.

PÉREZ RUIZ, Miguel Ángel. La publicidad en España. Anunciantes, agencias y medios. 1850-1950. Madrid: Fragua, 2001.

RODRÍGUEZ MARTÍN, Nuria. "Anunciar es vender. Nacimiento y desarrollo de la publicidad en la España del primer tercio del siglo XX". En: ALDUNATE LEÓN, O; HEREDIA URDÁIZ, I (Coords). Actas del I 
Encuentro de Jóvenes Investigadores de la AHC. Zaragoza: Prensas Universitarias de Zaragoza, 2008.

RODRÍGUEZ MARTÍN, Nuria. "Hábitos de consumo y publicidad en la España del primer tercio del siglo XX, 1900-1936". En: Actas de las VII Jornadas de Castilla-La Mancha sobre Investigación en Archivos, Archivo Histórico Provincial de Guadalajara, (Guadalajara, 15-18 noviembre 2005). Guadalajara: ANABAD, 2007, pp. 213-245. Disponible en: http://www.ucm.es/info/hcontemp/leoc/grupo/consumo.pdf [Consulta: 22/01/2012]

RODRÍGUEZ MARTÍN, Nuria. "La imagen de la mujer en la publicidad gráfica en España en el primer tercio del siglo XX". En: AMADOR, P., ROBLEDANO, J. y RUIZ, R. (eds.): $V$ Jornadas Imagen, Cultura y Tecnología. Madrid: Archiviana, 2007, pp. 383-399. Disponible en: http://orff.uc3m.es/bitstream/10016/9869/1/imagen_rodriguez_ICT_2007.pdf [Consulta: 22/01/2012]

RODRÍGUEZ MARTÍN, Nuria. "Los inicios de la prensa publicitaria en España: las revistas empresariales". En: IV Congreso Internacional de Prensa y Periodismo Especializado, (Guadalajara, 7-9 de mayo de 2008). Guadalajara: Asociación de la Prensa de Guadalajara, 2009. Disponible en: http://www.ucm.es/info/hcontemp/leoc/grupo/publicidad.pdf [Consulta: 03/06/2012]

RODRÍGUEZ MARTÍN, Nuria. "Ocio, consumo y publicidad. España: 18981920”. En: GÓMEZ-FERRER MORANT, G. (ed.): Modernizar España 1898-1914. Congreso Internacional: Comunicaciones, Madrid: Biblioteca Nueva, 2007. Disponible en: http://www.ucm.es/info//hcontemp/leoc/grupo/ocio.pdf [Consulta: 22/01/2012]

SÁNCHEZ GUZMÁN, José Ramón. Breve historia de la publicidad. Madrid: Ciencia 3, 1989.

SÁNCHEZ VIGIL, Juan Miguel. La Esfera: ilustración mundial (1914-1931). Madrid: Libris, 2003.

SÁNCHEZ VIGIL, Juan Miguel. Revistas ilustradas en España: del Romanticismo a la Guerra Civil. Gijón: Trea, 2008.

SÁNCHEZ VIGIL, Juan Miguel. El universo de la fotografia: prensa, edición, documentación. Madrid: Espasa-Calpe, 1999. 